
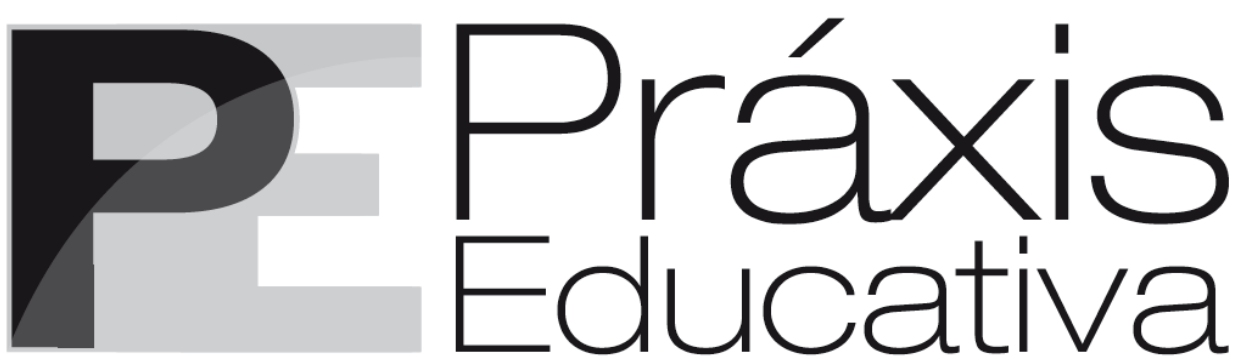

ISSN 1809-4031

elSSN 1809-4309

https://doi.org/10.5212/PraxEduc.v.16.17161.022

\title{
La liberación freiriana del sujeto en la Educación Matemática Decolonial Transcompleja
}

\section{A liberação freiriana do sujeito na Educação Matemática Transcomplex Descolonial}

\section{The freirian liberation of the subject in Decolonial Transcomplex Mathematical Education}

\author{
Milagros Elena Rodríguez* \\ iD http://orcid.org/0000-0002-0311-1705
}

\begin{abstract}
Resumen: La Educación Matemática en crisis hoy está convocada y demanda una liberación, pues es una práctica opresiva aún está en marco colonizador pese a grandes avances; urge liberar al sujeto de su práctica soslayadora. Como objetivo complejo se analiza la liberación freiriana del sujeto en la Educación Matemática Decolonial Transcompleja (EMDT); desde transmetodología transcompleja con la deconstrucción rizomática como transmétodo transcomplejo en la transmodernidad. Se trasciende en construcciones rizomáticas, complejas y transdisciplinares; ahondando desde Paulo Freire la crisis en la Educación Matemática hoy. En las conclusiones de aperturas, en la reconstrucción bajo la conciencia de que el legado freiriano siempre estará allí aportando buenas nuevas como un cántaro que no se agota, con una sabiduría de amor por la vida, con profunda fe en los educandos.
\end{abstract}

Palabras clave: Liberación freiriana. Educación Matemática. Decolonial.

Resumo: A Educação Matemática em crise hoje é chamada e exige uma libertação, pois é uma prática opressora e ainda se encontra em um quadro colonizador apesar dos grandes avanços; É urgente libertar o sujeito de sua prática evasiva. Como objetivo complexo, a libertação freiriana do sujeito é analisada em Transcomplex Decolonial Mathematical Education (EMDT); da transmetodologia transcomplex com a desconstrução rizomática como um transmétodo transcomplex na transmodernidade. É transcendido em construções rizomáticas, complexas e transdisciplinares; aprofundando de Paulo Freire a crise da Educação Matemática hoje. Nas conclusões iniciais, na reconstrução sob a consciência de que o legado freiriano estará sempre ali dando

\footnotetext{
* Docente Investigadora Postdoctoral del Departamento de Matemáticas, Universidad de Oriente, Venezuela. Doctora en Patrimonio Cultural de la Universidad latinoamericana y el Caribe (ULAC), Doctora en Innovaciones Educativas de la Universidad Nacional Experimental Politécnica de la Fuerza Armada Nacional Bolivariana (UNEFA). E-mail: $<$ melenamate@hotmail.com>.
} 
boas novas como uma jarra que não se esgota, com uma sabedoria de amor pela vida, com profunda fé nos alunos.

Palavras-chave: Libertação Freiriana. Educação matemática. Decolonial.

Abstract: Mathematics Education in crisis today is called and demands a liberation, since it is an oppressive practice and is still in a colonizing framework despite great advances; It is urgent to free the subject from its circumventing practice. As a complex objective, the Freirian liberation of the subject is analyzed in Transcomplex Decolonial Mathematical Education (EMDT); from transcomplex transmethodology with rhizomatic deconstruction as a transcomplex transmethod in transmodernity. It is transcended in rhizomatic, complex and transdisciplinary constructions; deepening from Paulo Freire the crisis in Mathematics Education today. In the opening conclusions, in the reconstruction under the awareness that the Freirian legacy will always be there providing good news like a jug that does not run out, with a wisdom of love for life, with deep faith in the students.

Keywords: Freirian liberation. Mathematics education. Decolonial.

\section{Rizoma transmétodo. Más allá de la metodología tradicional}

¡Volvemos a Paulo Freire; nunca nos fuimos!; siempre volver al último pedagogo latinoamericano cada vez que exista un oprimido es una tarea ineludible; allí siempre cuando la liberación se reclame donde la educación problematizadora clame. La convergencia del sentir de pedagogo de las favelas Paulo Reglus Neves Freire, el defensor de los desamparados, promotor del amor por el Sur: Paulo Freire invade los momentos actuales de la globalización que ínsita a la exclusión cada vez más, y así mientras tanto sigue resonando Paulo Freire donde quiera que exista un oprimido; donde los tentáculos de la substracción alcancen a la humanidad; hasta allí vive en cada clamor, justicia la conmemoración de los cien años del natalicio de Paulo Freire, digno de ser rememorado y hacerlo práctica y no sólo canción. La obra Freiriana, Freire más que nunca (KOHAN, 2020) está en exclamación permanente en poesía de la resistencia, conecta de manera amorosa el ser humano en muchas perspectivas, proyectos y categorías de liberación del sujeto: decolonial, compleja, transdisciplinar crítico, transcomplejo, ecosófico, antropoético, antropolítico; entre otras.

Es Paulo Freire quien justifica el ejercicio ético y político de la educación, afirmando que con la educación el hombre y la mujer va siendo y llegan a ser lo que son rehaciendo en el medio del hacer; la educación tiene sentido porque lo seres humanos se hacen y se rehacen aprendiendo, porque ellos pudieron asumirse como seres capaces de saber, de saber que saben, de saber que no saben. Va explicando el autor como lo seres humanos no pueden acabarse, acabados en formación, que esta es continua, concienciada y mejorada a través de la conciencia de inacabamiento de saber mejor lo que ya saben, de saber lo que todavía no saben. Sigue afirmando el pedagogo que la educación tiene sentido porque, para ser, los seres humanos necesitan estar siendo; si ya estuviesen acabados no se conversaría de educación (FREIRE, 2000).

Mientras, el estudio de la liberación freiriana es un ejercicio de estudio de la decolonialidad; Enrique Dussel en la visión bancaria de la educación, en su proyecto transmoderno, afirma que "el maestro dominador tiene como fundamento de su ethos una profunda desconfianza de su discípulo" (DUSSEL, 1975, p. 161); esa falta de fe la reitera Paulo Freire en todas sus obras, hablando de que se debe tener fe, que ese ser humano puede aprender; está en su derecho y capacidad; por ello me adelanto en el discurso y afirmo que creer que un discente no está capacitado para aprender matemáticas; que sólo unos poco aprenderán es un error de fe y antiética en contra de la condición humana de los

Práxis Educativa, Ponta Grossa, v. 16, e2117161, p. 1-15, 2021

Disponível em: <https://www.revistas2.uepg.br/index.php/praxiseducativa $>$ 
estudiantes; que desmitifica y desconoce el gran poder metacognitivo-afectivo-espiritual por explorar en el discente.

Paulo Freire en todos sus discursos busca un saber ecosófico, comprender que es necesario el arte de habitar en el planeta, para salir de la dominación; para emprender un ejercicio de superación de la pobreza e inclusión que invaden la vida en el planeta; refiere a la "palabra hueca de verbalismos alienantes" (FREIRE, 1970, p. 20) para relatar a la manera soslayadora como se domina con la educación; como esta es el proceso colonizador por excelencia para el proyecto modernista; a las falsas politicas sociales y educativas que ofrecen liberación a cambio de un puñado de centavos, un paño de agua caliente para callarlos.

Comprender a Paulo Freire en toda su complejidad es entender al ser humano que vivió y padeció por la liberación, la educación; por los oprimidos: abandonados del mundo, negados de la historia; "quién sabe, leer a Paulo Freire - sus obras, pero también su vida- nos enseña no solo las posibilidades de otra escuela y de otra educación, sino también de otra vida" (KOHAN, 2020, p. 95). Es esa la lucha Freiriana por una vida digna; es un ejercicio de amor profundo por el ser humano que Paulo Freire llevo en todo sentido. Queremos clarificar: ¿qué es el amor para Paulo Freire?; "el amor es un acto de valor, no de miedo, el amor es un compromiso con los demás. No importa dónde los oprimidos se encuentran, el acto de amor es el compromiso con su causa, la causa de la liberación" (FREIRE, 1970, p. 70)

Por otro lado, los aportes de Paulo Freire a la enseñanza de la matemática están aún por explorar; en la educación liberadora no hay una educación más bancaria y alienante que la Educación Matemática, este hecho está íntimamente relacionado con las políticas educativas y con la forma como concibe el docente la matemática como ciencia formal, inmutable y difícil de aprender; de cómo la utiliza como ejercicio de un poder, poder no circular; porque el saber matemático no circula. El poder es la capacidad que tiene un determinado sujeto de imponer su verdad, como la verdad para el otro. El poder crea la verdad, lo que existe es la verdad que el poder puede repetir hasta que un sujeto lo cree como su verdad. Tiene el poder de imponerla y sofocar otras verdades posibles (FOUCAULT, 1999). Así las situaciones, la enseñanza "dista mucho del aprendizaje y los conocimientos matemáticos no son transmitidos al corazón ni la vida de los discentes. Se establece en la escuela cuáles saberes serán sometidos y cuáles serán transmitidos” (RODRÍGUEZ; MOSQUEDA, 2015, p. 88).

En esta problemática el poder soslayado será descrito más adelante "la enseñanza dista mucho del aprendizaje y no es trasmitido en el corazón y en la vida de los discentes los conocimientos matemáticos, que establecen en la escuela cuales saberes serán sometidos y cuáles serán transmitidos" (RODRÍGUEZ, 2013a, p. 15). De tal manera, la matemática como legado de la humanidad es prohibitivo ante la vida del discente; ellos se pierde como sujetos pensantes de desarrollar procesos mentales esenciales para el desenvolvimiento en sus vidas como sujetos pensantes.

Por ello, más adelante tomaremos criticidad profunda en la crisis de la enseñanza de la matemática; en particular analizaremos desde las obras de Paulo Freire la dominación y exclusión del sujeto en dicha educación. Tomaremos preeminencia por su liberación en tanto las categorías discursivas como decolonialidad, transcomplejidad; entre otras, aparecen de manera compleja en todo el discurso; entramado con una transmetodología, más allá de las metodologías modernistas y manera de investigar. 
En tal sentido, se observa la denominación de rizoma en la estructura de la investigación; se trata de una anti-genealogía que rompe con las estructuras estáticas divisorias de presentar las indagaciones en las que las partes se dividen indisolublemente en un ir si un venir. Acá la organización no responde a ningún modelo estructural o generativo. El rizoma es un "sistema acentrado, no jerárquico y no significante (...) rizoma está hecho de mesetas (...) una región continua de intensidades, que vibra sobre sí misma, y que se desarrolla evitando cualquier orientación hacia un punto culminante o hacia un fin exterior" (DELUEZE; GUATTARI, 2004, p. 26). La palabra rizoma es una irreverencia al modernismo en el que se dividen las tradicionales investigaciones (RODRÍGUEZ, 2019).

En tanto, en la investigación como objetivo complejo se analiza la liberación freiriana del sujeto en la Educación Matemática Decolonial Transcompleja (EMDT); todo ello desde la deconstrucción rizomática como transmétodo transcomplejo en la transmodernidad (RODRÍGUEZ, 2019). Dicho transmétodo "busca el desmantelamiento de las epistemologías coloniales impuestas con la invasión al continente, pero igualmente la apertura hacia nuevos espacios que admitan a los sujetos subalternos, articular sus propias formas de conocimiento como la transcomplejidad, los saberes soterrados" (RODRÍGUEZ, 2019, p. 9). Acá se hace incisión en como la liberación del sujeto en la Educación Matemática.

Por ello, vamos a "deconstruir las relaciones jerárquicas del poder, para la liberación de la hegemonía y la reconstrucción de una sociedad política fundamentada en la solidaridad social, la antropoética, el amor por la tierra; la condición humana. Desde este sentido, deconstruir es también, descolonizar" (RODRÍGUEZ, 2019, p. 9); y decolonizar es liberar la practica opresiva de la matemática en el aula; y el sujeto es intricadamente el transmisor de la soslayación y el liberado en la indagación.

El sujeto investigador es liberado con sus subjetividades en el actor de conocer e investigar bajo los transmétodos; es víctima del proceso pero como doliente es agente de cambio

\begin{abstract}
No se trata de un investigador mecánico que sólo cumple con unos pasos cerrados e incambiables, es aquel que ha aprendido el difícil arte de habitar en el planeta y entiende que por muy particular que sean sus objetos de estudios estos deben coadyuvar en la salvación de la tierra. Si el carácter humano ante todo como un ser transdisciplinar y complejo que transciende a lo espiritual, ecológico, social, cultural; entre otras complejidades de la vida (RODRÍGUEZ, 2019, p. 11).
\end{abstract}

Declarando la profundidad de las obras de Paulo Freire en el aporte, en particular a la liberación del sujeto, vemos como el pedagogo sin duda en cada una de sus obra "es un individuo dotado de la facultad de representar, encarnar y articular un mensaje, una visión, una actitud, una filosofía u opinión" (SAID, 1996, p. 30). De ello, vamos a obtener grandes aportes a la problemática que nos convoca en la liberación del sujeto en la Educación Matemática, en un proyecto decolonial planetario.

En tanto el proyecto portador de la intencionalidad y hacer decolonial planetario la transmodernidad hace necesario un pensamiento crítico desde la exterioridad, la "transmodernidad más allá del mundo y del ser" (DUSSEL, 2004, p. 205). En esa exterioridad tanto Paulo Freire como Enrique Dussel propende rescatar al encubierto, al oprimido, al negado de la historia. Y la matemática como ciencia legado de la humanidad ha sido negada a muchos para hacer transcender en la vida de las personas y ayudarlos a realizarse en procesos metacognitivos de alto nivel.

En tal sentido, en una entrevista a George Papy, excelente matemático belga que aporto a la matemática y su educación en la Argentina afirma en una entrevista que le realizó Augusto Pérez que

Práxis Educativa, Ponta Grossa, v. 16, e2117161, p. 1-15, 2021 Disponível em: <https://www.revistas2.uepg.br/index.php/praxiseducativa $>$ 
Los niños o individuos que han estado bloqueados para aprender matemáticas, han estado bloqueados también en su personalidad. Un niño que no aprendió matemáticas se siente disminuido en sí mismo como individuo. Se puede hablar, pues, de una relación profunda entre el conocimiento matemático y las personalidades (PÉREZ, 1980, p. 4).

A esa magnitud llega el ejercicio bancario de la Educación Matemática. Nótese como la soslayación, la crisis en la enseñanza de la matemática, en su liberación propendida y clamada en esta investigación, que explicaremos más adelante; nótese como pueden soslayarse los discentes con la matemática tronchada de sus procesos más vitales y esenciales en el aula, y se llega al extremo de bloquear los discentes y llegar a tener una personalidad cohibida, subsumida en la falta de autoestima y afectada para aprender otros saberes.

La línea de investigación en la que se enmarca esta investigación, la Educación Matemática Decolonial Transcompleja, es liberadora, inclusiva, ecosófica y transmoderna (RODRÍGUEZ, 2020a), pues el repensamiento que conlleva a la "Educación Inclusiva Ecosófica se da en un proyecto transmoderno en el que no hay posibilidad, para el encubrimiento del otro, ni medidas de opresión que se permitan; los topoi van como un nuevo conocimiento al abrazo de grupos considerados disímiles" (CARABALLO; RODRÍGUEZ, 2019, p. 130). Se trata de posturas libertarias, que propenden la salvaguarda de la matemática en la vida de las personas.

Declaramos que la transcomplejidad que anida una visión compleja y transdisciplinar es un ejercicio liberador onto-epistemológico, "este pensamiento transcomplejo ha construido conceptos científicos educativos muy importantes como aula mente social, emergentes educativos, metacomplejidad, deconstrucción educativa y complejidades curriculares" (GONZÁLEZ, 2014, p. 13). Así, la presente investigación que es transcompleja sienta las bases "de un nuevo episteme orientado hacia el renacer de la conciencia del ser humano, un saber ecosófico que nos lleve a des-ligar sabiamente para volver a ligar" (RODRÍGUEZ, 2020b, p. 175) los procesos dialógicos-dialécticos de los actores del proceso educativo de la matemática.

Y justamente la opresión la obra la Educación como práctica de la libertad, la define como una relación violenta, "a un tiempo, desamor y un impedimento para el amor" (FREIRE, 1976, p. 43). Y eso ha sido la práctica soslayadora de la matemática, que propendemos profundizar desde las obras de Paulo Freire en el siguiente rizoma donde la deconstrucción juega un papel esencial.

\section{Rizoma crisis. Paulo Freire en la crisis de la Educación Matemática hoy}

La educación opresora de la matemática hoy, puede recurrir a las obras freirianas para ejemplificar lo que ocurre en la enseñanza; de donde deviene la crisis y como la Educación Matemática hereda la opresión modernista-colonial del proyecto de soslayación que comenzaría en 1492 con la invasión al Sur; y que se permuta con instrumentos soslayadores globalizantes del Norte. En Paulo Freire se consiguen esencias de liberación a la Educación Matemática dignas de ser reconstruidas a la luz de los preceptos innovadores y creativos; unidos al rescate del patrimonio matemático desde el patrimonio histórico de las civilizaciones encubiertas.

Paulo Freire señala las faltas en el sistema tradicional de educación y cómo sirve a los opresores. Imprime el pedagogo que "el educador aparece como su agente indiscutible, como su sujeto real, cuya tarea indeclinable es 'llenar' a los educandos con los contenidos de su narración” (FREIRE; 1970, p. 71); llenarlos de fórmulas, algoritmos, teoremas, todos importantes pero la manera que son depositados

Práxis Educativa, Ponta Grossa, v. 16, e2117161, p. 1-15, 2021

Disponível em: < https://www.revistas2.uepg.br/index.php/praxiseducativa $>$ 
en el estudiante es rígida sin comprensión; sin pasar de lo abstracto a lo concreto y viceversa. Es por ello, que mientras más se deposite en las mentes pasivas de los educandos más exitosos se sentirán los opresores (RODRÍGUEZ; MOSQUEDA, 2015); mientras más inyecten algoritmos sin sentido en la vida de los discentes más empoderados como opresores sentirán los docentes de matemáticas.

Sin duda, Paulo Freire ya va clasificando este sistema educativo de la matemática como una concepción bancaria, la Educación Matemática hoy es un reflejo o caso particular de la educación bancaría; sin duda hay un deposito sin sentido, sin la: cotidianidad, subjetividad, procesos dialógicos de los estudiantes; conocimientos previos; depositados los conceptos, reglas, formulas, teoremas, ejemplos y ejercicios a repetir tal cual el deposito; donde la abstracción es la reina y la concreción el mendigo; y queremos dejar sentado que abstracción-concreción nunca se separan (PEÑALVA, 2010).

Es de hacer notar, que en esa educación bancaria de la matemática, "cuando más vaya llenando los recipientes con sus "depósitos", tanto mejor educador será. Cuanto más se dejen "Ilenar" dócilmente, tanto mejor educandos serán” (FREIRE, 1970, p. 72). A esta opresión que aceptan pasivamente los educandos a la que convoca a que deben liberarse, pues son los oprimidos los que conocen y sufren su realidad. Desde luego, la pasividad del educando deviene que ya fue clasificado como flojo o negligente, no inteligente; no está en la franja a considerar como candidato para aprender matemática ejemplarmente; la Educación Matemática así concebida es antidemocrática (SKOVSMORE, 2012).

Los estudiantes de matemática en tal sistema pedagógico de la ciencia legado de la humanidad, negada en la vida de los seres humanos, crea como consecuencia de su opresión dicentes tan pasivos que "el único margen de acción que se ofrece a ellos es el de recibir los depósitos, guardarlos y archivarlos" (FREIRE, 1970, p. 72); con especial atención que en matemática el problema de todos los problemas es que no es fácil archivar en las mentes lo que no tiene sentido presentado sin historia, filosofía; fuera de la belleza del avance de las civilizaciones gracias a un gran aporte de las matemáticas; ejemplo de ellas la civilizaciones Mayas y Egipcias negadas y ocultada por año; opresión negadora de que los Mayas son los primeros en inventar el cero; representado de manera mística, práctica, y natural en sus vidas y cotidianidades.

Es así como, el único que sabe en esta relación opresor-oprimido es el docente, "el dueño exclusivo de la información que será depositada, el educador siempre va a ser él que sabe, en tanto los educandos serán siempre los que no saben" (FREIRE, 1970, p. 73). Rezagos serios de esta educación bancaria existen aún en nuestro sistema educativo en la matemática, y es como se conocen los casos que cualquier solución o representación de los conceptos matemáticas que no devienen de la repetición estricta de lo dado por el docente son castigados; así como se castiga el error; y en la mayoría de los casos no se considera el proceso de aprendizaje desde el estudio de la maneta como avanza el discente cada vez que comente errores. "Lo más grave es que frecuentemente no existe en la conciencia ideológica la menor culpabilidad por el acto docente encubridor, falso” (DUSSEL, 1975, p.161).

En la relación: opresores-oprimidos, los opresores consideran que sólo ellos son persona bumana, los otros son cosas objetos, y como tal son tratados. Los opresores tienen una conciencia opresora que transforma todo aquello que le es cercano en objeto de su dominio (RODRÍGUEZ; MOSQUEDA, 2015); por ello la Educación Matemática irrespeta la condición humana; cuando atenta contra el proceso de ascensión a la abstracción en la vida del niño y niña; cuando impone juegos y procesos que no son de su cultura y vida; pero también la Educación Matemática dirigida e impuesta por el docente irrespeta antiéticamente

Práxis Educativa, Ponta Grossa, v. 16, e2117161, p. 1-15, 2021 Disponível em: <https://www.revistas2.uepg.br/index.php/praxiseducativa $>$ 
a los proyectos de vida del estudiante, y puede causar problemas psíquicos en el estudiante (PÉREZ, 1980).

Ésta tendencia a imaginar todo y a todos, tiene su base en el empeño de posesión. El dominio sobre otra persona, es una tendencia del sadismo; cuyo fin es convertir a la persona en objeto; el objeto que debe desarrollar competencias para servir a un sistema, donde su ser, ser persona y ciudadanía queda relegada; el acto de ser feliz como humanos aprendiendo matemáticas, disfrutando, jugando al geómetra es prohibitivo en la enseñanza de la matemática. Es esta típica relación epistemológica sujetoobjeto entre docente y estudiante aún presente.

En este momento iqué pasa con los oprimidos, porque no intentan liberarse de la práctica opresora de la Educación Matemática? Los oprimidos no alcanzan a ver que alojan al opresor dentro de sí. Hay un auto desvalorización y ejercen un tipo de violencia horizontal; han legitimado de manera universal que aprender matemática es difícil, que es inalcanzables; los niveles de rechazo y falsas creencias en contra del proceso educativo de la matemática son muy altos; así como en contra del docente. El dilema que tienen los oprimidos es, seguir las prescripciones o tener opciones. Los oprimidos se sienten entonces claramente desmejorados y creyentes de que en verdad son inferiores; concepción reforzada siempre por la educación bancaria; no sólo de la matemática; pero que en ella se hace patente crudamente.

\begin{abstract}
En la visión bancaria de la educación, el saber, el conocimiento, es una donación de aquellos que se juzgan sabios a los que juzgan ignorantes. Donación que se basa en una de las manifestaciones instrumentarles de la ideología de la opresión: la absolutización de la ignorancia, que constituye lo que llamamos alienación de la ignorancia, según la cual ésta se encuentra siempre en el otro. El educador que aliena la ignorancia, se mantiene en posiciones fijas, invariables. Será siempre el que sabe, en tanto los educandos serán siempre los que no saben. La rigidez de estas posiciones niega a la educación y al conocimiento como procesos de búsqueda (FREIRE, 1970, p. 73).
\end{abstract}

La tendencia a declarar rechazo hacia el docente ha llevado hasta el extremo que lo discentes actualmente con el desarrollo de programas tecnológicos prefieren dicho instrumento pues no castiga; sólo que prescindir en los primeros niveles educativos de un docente ejemplar queda cuesta arriba para los discentes. Así mismo, el deseo de oprimir, la regularización del docente de matemática difícil e impositivo se ha normalizado; claramente mayor satisfacción sienten los opresores cuando los oprimidos dejan y aceptan el depósito. Desde luego, comienza a emerger tomas de conciencias y estudios en líneas de investigaciones decoloniales de como liberarse del proceso opresor de la Educación Matemática; esto lo veremos en el próximo rizoma en la reconstrucción de la liberación onto-epistemológica del sujeto en la EMDT.

Desde luego, el opresor siente un fracaso, cuando el oprimido se revele y no acepte pasivamente dicho depósito; y así tradicionalmente el docente arremete contra la humanidad del discente calificándolo de no inteligente; imposibilitándolo su capacidad metacognitiva de alto nivel que está allí subyacente; esperando ser despertada del letargo de la pasividad y empoderarse de la ciencia más bella de la humanidad que marca pautas y aportes en todos los saberes; merecen las personas empoderarse de dicha ciencia y desarrollar proceso dialógicos - dialecticos que les hagan desarrollarse como ser sentipensante que vaya a aporta a la necesaria re-civilización de la humanidad. Tal opinión fría, en el docente, en realidad con lo que ocurre es que la educación bancaria "sólo puede interesar a los opresores que estarán tanto más tranquilos cuanto más adecuados sean los hombres al mundo. Y tanto más preocupados cuanto más cuestionen los hombres el mundo” (FREIRE, 1970, p. 79).

Práxis Educativa, Ponta Grossa, v. 16, e2117161, p. 1-15, 2021

Disponível em: <https://www.revistas2.uepg.br/index.php/praxiseducativa $>$ 
Con todo esto, es entendible que los dominadores u opresores se ven en la obligación justa para ellos conveniente en sus mentes es el de dificultar al máximo el pensamiento auténtico de sus opresores (RODRÍGUEZ; MOSQUEDA, 2015). Desde luego, Paolo Freire ha manifestado que estos opresores también están enfermos; he allí una gran verdad no hay posibilidad de oprimir sin ser oprimido; así oprimido-opresor en la matemática se intercambian; en tanto ese ser que oprime el docente será el opresor pronto en la vida de las personas que toque con sus acciones. La intención ahora es ir más allá a la liberación de la opresión. Y que el docente deviene en su formación de una relación opresora del sistema colonial que le ha impuesto una manera de educar en la matemática, en la que el docente no se ha liberado sino que en su comodidad desde su conocer escueto de lo que es verdaderamente la matemática el pregona.

La liberación no puede resultar de una educación bancaria según Freire, no se puede liberar el oprimido bajo la misma educación opresora; que es colonial; el sentido decolonial planetario es de indispensable valor. Por ello, el pedagogo opina que "la liberación auténtica es la humanización en el proceso" (FREIRE, 1970, p. 84), esta humanización ya no se deposita, no es impuesta es liberadora. Hay que tomar conciencia que al oprimido se le ha subestimado, no se ha creído que el piense valiosamente, que el invente, que él pueda resurgir; se rechaza cualquier cuestión importante que desde sus mentes pueda surgir.

En tal sentido, la enseñanza de la matemática liberadora que propende en la línea de investigación: Educación Matemática Decolonial Trancompleja, es la educación que se

Impone a los que verdaderamente se comprometen con la liberación no puede fundarse en la concepción de los hombres como vasos a los que el mundo echa los contenidos; no puede basarse en una conciencia especializada, mecánicamente compartimentada, sino en hombres como cuerpos cocientes y en la conciencia como conciencia proyectada en el mundo (FREIRE, 1985, p. 79).

De ahí la toma de conciencia de lo significa enseñar matemática de manera compleja y transdisciplinar es salirse de la ciudadela de la disciplina e indisciplinarlas a fin de que en la complejización de todos los saberes se consigan esencialidades para enseñar matemática con mente, cuerpo y corazón liberando a los actores educativos.

Por último, ya iniciando la reconstrucción que el transmétodo propende, es de clarificar que acudir a la cotidianidad, partir de los conocimientos del dicentes, no centrar la práctica de la enseñanza de la matemática en la repetición es de atención cuidado de acuerdo con Paulo Freire,

No hay cómo no repetir que enseñar no es la pura transferencia mecánica del perfil del contenido que el profesor hace al alumno, pasivo y dócil. Como tampoco hay cómo no repetir que partir del saber que tengan los educandos no significa quedarse girando en torno a ese saber. (...) el profesor o la profesora solo enseñan en términos verdaderos en la medida en que conocen el contenido de lo que enseñan, es decir, en la medida en que se lo apropian, en que lo aprenden (FREIRE, 1992, p. 92 y 105).

En tal sentido, la cotidianidad, cultura, las subjetividades del discente junto a la historia y filosofía de la matemática aportan sustantivos liberadores esenciales.

Práxis Educativa, Ponta Grossa, v. 16, e2117161, p. 1-15, 2021

Disponível em: <https://www.revistas2.uepg.br/index.php/praxiseducativa> 
Milagros Elena Rodríguez

\section{Rizoma reconstrucción. La liberación freiriana del sujeto en la Educación Matemática Decolonial Transcompleja}

La obra de Paulo Freire tiene un sello, una marca universal, una palabra que nos convida a hacer de la praxis una realidad; esta palabra es: LIBERACIÓN; si como está escrita con mayúscula, que es un grito de urgencia. Quiero hacer énfasis en la liberación con mayúscula; si como lo es al mismo tiempo liberar la practica opresora de la matemática en la educación. Nos preguntamos: ¿existe liberación si decolonialidad?, ¿es la decolonialidad planetaria liberadora? Parecen retoricas nuestras preguntas. Vamos a responder de manera general y luego bajo ese norte iremos a la línea de investigación; que funge como categoría y fin de la indagación: la Educación Matemática Decolonial Transcompleja. Por ello, vamos a "una reconstrucción esperanzadora que intercede en el discurso, lo derriba para levantar algo nuevo desde la perspectiva de totalidad, de completitud, de complejidad de su estructura y sus infinitas posibilidades de asociación, cuya edificación se erige en el momento de decidir” (RODRÍGUEZ, 2019, p. 9).

La obra freiriana un antecedente y presentación que ha venido apresurando la decolonialidad planetaria; la concepción compleja del pedagogo latinoamericano sobre la concepción ético-política de la educación, los desarrollos teóricos y prácticos en torno a la educación, la relación opresor-oprimido, la relación poder-saber, el sendero de la liberación es clave en la Educación Matemática Decolonial Transcompleja. Creemos que esta evidente que no hay liberación sin decolonialidad; más pese a ello el discurso reconstructivo seguimos ahondando en esa primera pregunta.

En cuanto a la segunda pregunta; la principal finalidad de la decolonialidad planetaria es la liberación. Ahora, ¿la liberación de qué?, del sujeto, de las mentes, del hacer, ser, pensar del soñar en general en todas partes la marca de liberación está presente a fin de que en el proceso liberador ocurra el asunto de empoderarse de las vidas, comunidades y del sentipensar que hace presencia en la liberación del sujeto. Freire y Fanon acuden y asumen al grito/llanto del condenado. Efectivamente restauran la ética "dándole lugar humano a las diferencias ontológicas y trans-ontológicas" (MALDONADO-TORRES, 2007, p. 152).

Debemos hacer notar la justa relación de la diada: liberación-decolonialidad planetaria; es notorio que desde los orígenes de la historia de Paulo Freire y Frantz Fanon existe un estrecho vínculo entre la propuesta política de Fanon y la forma que Freire le da a su obra cumbre la pedagogía del oprimido. No cabe duda que Freire es examinado por los escritos de Fanon Piel Negra Máscaras Blancas y Los Condenados de la Tierra, este último de enorme influencia en Pedagogía del Oprimido (YEDAIDE, 2014); palabras Inés Fernández Mouján sobre Fanon, Freire y las posibilidades concretas de una pedagogía descolonial, entrevista realizada por María Marta Yedaide. Las ideas de liberación y descolonización en la que Freire reencuentra a Fanon y se funden en su objetivo complejo de liberación-decolonialidad.

Ahora, ¿ de qué se trata la liberación freiriana del sujeto en la educación Matemática Decolonial Transcompleja? Vamos a inmersionarnos más en la EMDT. La Educación Decolonial Transcompleja tiene esencia compleja y transdisciplinar que puede generar, otro sujeto en la universidad, en pensamiento y práctica, en re-ligar des-ligando primeramente, en aprovechar la incertidumbre sin aprensión a errar; "hacer de la ciencia en su práctica y concepción no tan inmersa en universalidades, método programático o demostraciones modeladas basadas en la rigidez y búsqueda de verdades que son solo momentáneas" (GONZÁLEZ, 2015, p.85).

En particular en la Educación Matemática, la "transdisciplinariedad conlleva un cambio de paradigma en la visión cognoscitiva que implica ver más allá de las disciplinas y entender ese todo, para

Práxis Educativa, Ponta Grossa, v. 16, e2117161, p. 1-15, 2021

Disponível em: <https://www.revistas2.uepg.br/index.php/praxiseducativa $>$ 
organizar diseños curriculares capaces de propiciar la construcción de los conocimientos que superan las disciplinas aisladas" (CÓRDOBA, 2014, p. 191), ello implica un cambio en los currículos, en la didáctica, en la formación docente, los ambientes de aprendizaje y en general, una nueva epistemología de las instituciones educativas de la Educación Matemática; lo que lleva a una nueva con-formación del ciudadano (RODRÍGUEZ, 2013b).

Es de hacer notar que enseñar matemática en los aborígenes, en las favelas, en Sur se necesita la altersofía, la otra sabiduría de la matemática, que

Garantiza, reproduce y conserva el vivir del sujeto subalterno y es la base y cimiento teórico y praxiológico del hacer decolonial como proceso decolonizante. Ambos, la altersofía y el hacer decolonial, (...) constituyen una diada o bina sófica (no epistémica) potenciadora del pensamiento alterativo en función de configurar convivires comunales (ORTIZ; ARIAS, 2019, p. 82).

Esos saberes deben ser resaltados y dialogantes en la Educación Matemática Decolonial Transcompleja; ellos deben ser protagonistas de la academia, de la otra forma de conocer matemática en el Sur y desde el Sur (RODRÍGUEZ, 2020c).

Por otro lado, en la obra Cartas a quien pretende enseñar Paulo Freire afirma que "el educador aprende primero a enseñar, pero también aprende, al enseñar, algo que es reaprendido por estar siendo enseñado" (FREIRE, 1993, p. 46); ocurre la crítica de la praxis del docente de matemáticas la relación enseño-aprendo-reaprendo, la estudiante-docente, docente- estudiante en permanente combinación. El educador de la matemática se transforma en educador-educando y los educandos en educandoeducador. En este acaecimiento dinámico, los educandos son agentes activos en el proceso educativo de la matemática y al superar sus estados pasivos, ya no son herramientas que sirven a los opresores (RODRÍGUEZ; MOSQUEDA, 2015). En este sentido, "éstos, en vez de ser dóciles receptores de los depósitos, se transforman ahora en investigadores críticos en diálogo con el educador, quien a su vez es también un investigador crítico" (FREIRE, 1970, p. 88) denomina ahora a este tipo de educación una educación problematizadora que exige la reflexión y que implica un acto permanente de descubrimiento de la realidad.

Hay que problematizar la Educación Matemática, es deseable "siempre un sujeto cognoscente, tanto cuando se prepara como cuando se encuentra dialógicamente con los educandos" (FREIRE, 1970, p. 91). La educación problematizadora que sólo se da desde una pedagogía problematizadora, "se empeña en la desmitificación" (...) la educación bancaria niega el diálogo en tanto que la educación problematizadora tiene en él la relación indispensable con el acto cognoscente, descubridor de la realidad" (FREIRE, 1970, p. 91). Ese develar, deconstruir transmetódicamente que es decolonizar, y al mismo tiempo liberar, mostrando en escena la soslayación que se viene dando en la enseñanza; por ello abra que revisar la intencionalidad, las carencias, las integridades del ser humano discente que en un dialogo muestras sus necesidades que necesitan sean tomados en cuenta y la profunda fe en que ellos pueden aprender y tiene esencias matemáticas desde su modos de vida.

Claramente se trata de un cambio radical, de una liberación; es por ello, que el pedagogo enfatiza que esta transformación educativa, esta vez de la matemática, no tiene sentido si los oprimidos quieren meramente asumir el puesto ocupado previamente por sus dominadores "este movimiento de búsqueda sólo se justifica en la medida en que se dirige al ser más, a la humanización de los hombres" (FREIRE, 1970, p. 94). Nunca es un trabajo que se puede hacer de una manera individualista. Esto ha pasado en el aula, que unos pocos estudiantes aventajados son denominados inteligentes y están en la

Práxis Educativa, Ponta Grossa, v. 16, e2117161, p. 1-15, 2021

Disponível em: <https://www.revistas2.uepg.br/index.php/praxiseducativa $>$ 
franja de los dominadores que le dicen a los otros que no pueden hacerlo. En algunas prácticas notorias de celebrar ellos son animadores con un yo sí puedo encontrando vías alterna para que sus compañeros encuentren las suyas.

El oprimido debe estar consciente que la liberación no es fácil, "es un parto. Es un parto doloroso. El hombre que nace de él es un hombre nuevo, hombre que solo es viable en la y por la superación de la contradicción opresores-oprimidos que, en última instancia, es la liberación de todos" (FREIRE, 1970, p. 34). La contradicción opresor-oprimido puede superarse en la Educación Matemática si hay un cambio de percepción del mundo opresor, si hay una expulsión de los mitos creados y desarrollados en la estructura opresora y si hay una transformación de la situación concreta que genera la opresión (RODRÍGUEZ; MOSQUEDA, 2015).

Pero bajo la concepción y conciencia práctica de hacer matemática en la vida de los seres humanos el docente debe tomar conciencia de la gran responsabilidad que tiene; por ello debe conocer de la naturaleza de la condición humana, de cómo el discente aprende; de la forma como viene concibiendo la matemática en sus juegos en los primeros niveles educativos expresa que en una educación problematizadora "cuanto más investigo el pensar del pueblo con él, más nos educamos juntos. Cuanto más nos educamos, tanto más continuamos investigando. Educación e investigación temática, en la concepción problematizadora de la educación, se tornan momento de un mismo proceso" (FREIRE, 1970, p. 94).

El docente de matemáticas debe saber que ahora, ya nadie educa a nadie, así como tampoco "nadie se educa a sí mismo; los hombres se educan en comunión, y el mundo es el mediador. Mediadores son los objetos cognoscibles que, en la práctica "bancaria", pertenecen al educador, quien los describe y los deposita en los pasivos educandos" (FREIRE, 1970, p. 90); pero que ahora en la liberación del sujeto los objetos cognoscibles pertenecen al mundo subjetivo-objetivo por construir, mediar y aceptar.

Por tanto, el docente debe comenzar junto a sus estudiantes a des-ligarse de la vieja práctica opresora; en la medida que se va formando y conformando en categorías esenciales del ser y hacer matemática legado de la humanidad no opresora denominada Occidental; ahora apellida la matemática como humanidad; y re-ligar con ello los saberes matemáticos de la cultura, cotidianidad; aquellos olvidados y execrados por privilegiar la práctica hegemónica de la matemática. En ese re-ligar en vías de construcción, es improrrogable la atención a las condiciones que se producen por desconocimiento, ligereza, anticientificismo, debilidades conformativas, críticas a la praxis y falta de contextualización del pensamiento complejo, de la complejidad como imposibilidad de pensar dentro del pensamiento modernista (RODRÍGUEZ, 2020b).

Es importante que el docente salga de la ciudadela colonial tradicional en dicha educación que deje la negación de los tradicionalistas a innovar y pensar complejamente; que aquejan a una gran parte de los educadores de la matemática, maestros, profesores donde es menester acercarse al estudio del pensamiento complejo; "muchos han comenzado a emerger en cambios transmodernistas que dejan resultados importantes en las investigaciones e instituciones; el reconocimiento de la transdiciplinariedad" (RODRÍGUEZ, 2020b, p. 185).

La necesidad de una transformación radical del sistema educativo de la matemática del Sur heredado del colonizador, se requiere una proposición educativa que conciba que el conocimiento matemático no es algo concluido, acabado y donado por el educador, que se hace necesario reflexionar

Práxis Educativa, Ponta Grossa, v. 16, e2117161, p. 1-15, 2021 
La liberación freiriana del sujeto en la Educación Matemática Decolonial Transcompleja

nuevas representaciones de educar, una perspectiva provocadora en la que los discentes ahonden la noción de que lo fundamental es sentirse sujetos de la historia una praxis destinada a subvertir las prácticas educativas de la matemática coloniales e impuestas, al mismo tiempo que implica una racionalidad que pone en jaque toda imposición (RODRÍGUEZ, 2020b), por ello acudir a los procesos dialógicos-dialécticos de las civilizaciones olvidadas: las mayas por ejemplo es reconstruir el patrimonio matemático reconstruyendo y salvaguardando su inmenso legado de la matemática; los mayas inventores del cero, con un sistema posicional vigesimal de excelencia pues servir para cuestionar la alienación en la que educandos y educadores están sumergidos; la crítica se encauza hacia la práctica docente domesticadora, dejando al educando al margen de la búsqueda y de la praxis (FREIRE, 1970).

Es importante regresar a la conjunción de los procesos metacognitivos de alto nivel en la matemática procesos que no se desunen: concreción-abstracto, ejemplo-teoría, local-global, entre otros. Generar salidas en la preeminencia de la crisis educativa de la matemática como la que permea a las demás crisis educativas de todos los saberes y la vez al atacar la crisis educativa total, de sus políticas, de lo que significa educar, hay que des-ligar el currículo oculto de la apropiación compleja y transdisciplinar; en tanto estas últimas le encubren la verdadera intencionalidad de dicho programa colonial de soslayamiento. Es de considerar que, "mi esfuerzo se dirige a vincular lo empírico y lo teórico, lo concreto y lo abstracto, la parte y el todo, el fenómeno y el contexto" (MORÍN, 1996, p. 276); estas ideas deben hacerse realidad y la Educación Matemática Decolonial Transcompleja la propende.

\section{Rizoma final. Aperturas a la Educación Matemática Decolonial Transcompleja}

Se ha cumplido de manera compleja y transdisciplinar con el objetivo complejo de analizar la liberación freiriana del sujeto en la Educación Matemática Decolonial Transcompleja; todo ello desde la deconstrucción rizomática como transmétodo transcomplejo en la transmodernidad. Las obras de Paulo Freire han sido de un valor extraordinario en ello; es un recorrido que apenas comienza en la línea de investigación EMDT; por ello las tentativas por explorar comienzan a conformarse.

Desde ese diálogo de amor freiriano que hemos venido describiendo, en valorizar al otro, el saber que lo que dice es importante, que es inteligente ese discente que espera sus miedos y predisposiciones sean minimizados y se despierte su amor por la matemática; solidaridad que rompen las cadenas de la relación opresor-oprimido y así una verdadera liberación. Es la construcción hacia una matemática viva y mostrada desde luego en todas sus facetas, cualidades y belleza; mediante una Educación Matemática Decolonial Transcompleja realmente liberadora. La ciencia con su historia y filosofía en el aula, con toda la complejidad que implica develando la sometida a encubrimiento que espera ser mostrada en su esencia; como por ejemplo la matemática de las civilizaciones mayas, olmecas, egipcias.

El legado freiriano siempre estará allí aportando buenas nuevas como un cántaro que no se agota, con una sabiduría de amor por la vida, con profunda fe en los educandos; Paulo Freire el último pedagogo latinoamericano clama en cada una de sus obras por no ser el último y volver sobre su lectura siempre como deber de vida a beber de esa sabiduría. La Educación Matemática estuvo y estará siempre invitada; a revisar sus prácticas a la luz de las obras del pedagogo. Acá hemos continuado en la línea de investigación que seguramente, aun cumpliendo el objetivo complejo, hay mucho que decir en el entramando hace freiriano. Hagámoslos valer en nuestro corazón, conciencia, formación y ejercicio.

Práxis Educativa, Ponta Grossa, v. 16, e2117161, p. 1-15, 2021

Disponível em: <https://www.revistas2.uepg.br/index.php/praxiseducativa $>$ 
El trabajo Freiriano es un gran empuje para la solución del problema de la enseñanza tradicional de la matemática, Paulo Freire se nutrió en el constructivismo, de un trabajo integral en el propio campo de batalla de los problemas. Es hora de que nos apropiemos del legado Freiriano; desde luego que no se trata de recetas acabadas, Paulo Freire nunca impuso eso una aplicación mecánica de sus concepciones, se trata de acuerdo con nuestras condiciones específicas en el aula de que nos inspiremos en el gran pedagogo y procedamos como él hubiese querido: a investigar y estudiar nuestras condiciones, a actuar, a jugar nuestro rol pedagógico liberador de la opresión del proceso educativo de la matemática y nuestro papel transformador en el aula.

En la parte final en caminos de la liberación del sujeto como acto de amor, como Cristiana, en la ecosofía espiritual, la palabra de Dios que alumbra, le doy la gloria a Dios siempre en el nombre de mi salvador Jesucristo; les afirmo la sagrada palabra: "Toda Escritura es inspirada de Dios y provechosa para enseñar, para censurar, para rectificar las cosas, para disciplinar en justicia” (BIBLIA DE JERUSALÉN, 2 Timoteo 3,16).

\section{Referencias}

BIBLIA DE JERUSALÉN. São Paulo: Paulus, 2002.

CARABALLO, M.; RODRÍGUEZ, M. E. Perspectivas complejas y antropoéticas de la educación inclusiva ecosófica. Polyphônia: Revista de Educación Inclusiva, v. 3, n. 2, p. 117-133, ago./dec. 2019.

CÓRDOBA, M. Superar la fragmentación para ver el bosque. Documentos INTEC, v. 21, p. 181204, 2014.

DELUEZE, G.; GUATTARI, F. Mil mesetas: capitalismo y esquizofrenia. Valencia: Pre-textos, 2004.

DUSSEL, E. Hacia una pedagógica de la cultura popular en cultura popular y filosofía de la liberación. Buenos Aires: Fernando García Cambeiro, 1975.

DUSSEL, E. Sistema mundo y transmodernidad. En: SAURABH, D.; ISHITA, B.; WALTER, M. (ed.). Modernidades coloniales. México: El Colegio de México, 2004. p. 201-226.

FOUCAULT, M. Estrategias de poder. Buenos Aires: Ediciones Paidós Ibérica S. A., 1999. (Colección Obras Esenciales, v. II).

FREIRE, P. Pedagogía del oprimido. Buenos Aires: Siglo XXI, 1970.

FREIRE, P. Educación como práctica de la libertad. Buenos Aires: Siglo XXI, 1976.

FREIRE, P. ¿Extensão ou comunicação? Rio de Janeiro: Paz e Terra, 1985.

FREIRE, P. Pedagogía de la esperanza: un reencuentro con la Pedagogía del oprimido. Buenos Aires: Siglo XXI, 1992.

FREIRE, P. Cartas a quien pretende enseñar. 6 ed. Buenos Aires: Siglo XXI, 1993. 
FREIRE, P. Pedagogía de la indignación: cartas pedagógicas en un mundo revuelto. Buenos Aires: Siglo XXI, 2000.

GONZÁLEZ, J. Paradigma educativo transcomplejo educación del siglo XXI. Revista Ciencias Farmacia y Bioquímica, v. 2, n. 1, p. 11-16, 2014.

GONZÁLEZ, J. Religaje educativo: espacio-tiempo. Barranquilla: Ediciones Universidad Simón Bolívar, 2015. (Tomo V).

KOHAN, W. Paulo Freire más que nunca: una biografía filosófica. Buenos Aires: CLACSO, 2020.

MALDONADO-TORRES, N. Sobre la colonialidad del ser: contribuciones al desarrollo de un concepto. En: CASTRO-GÓMEZ, S.; GROSFOGUEL, R. (ed.). E1 giro decolonial: reflexiones para una diversidad epistémica más allá del capitalismo global. Bogotá: Iesco-Pensar-Siglo del Hombre Editores, 2007. p. 127-167.

MORÍN, E. Mis demonios. Barcelona: Editorial Kairós, 1996.

ORTIZ, A.; ARIAS, M. Altersofía y hacer decolonial: epistemología "otra" y desprendimiento de la Metodología de Investigación. ESTUDIOS: Utopía y Praxis Latinoamericana, v. 85, p. 76-103, 2019.

PEÑALVA, L. Las matemáticas en el desarrollo de la metacognición. Política y Cultura, n. 33, p. 135-151, 2010.

PÉREZ, A. Las matemáticas modernas: pedagogía, antropología y política. Entrevista a George Papy. Perfiles Educativos, v. 10, p. 41-46, 1980.

RODRÍGUEZ, M. E. El poder que se practica, analizado desde Michel Foucault, en la enseñanza de la matemática. Praxis Educativa ReDIE, n. 9, p. 7-24, nov. 2013/abr. 2014, 2013 a.

RODRÍGUEZ, M. E. La educación matemática en la con-formación del ciudadano. TELOS: Revista de Estudios Interdisciplinarios en Ciencias Sociales, v. 15, n. 2, p. 215-230, 2013b.

RODRÍGUEZ, M. E. Deconstrucción: un transmétodo rizomático transcomplejo en la transmodernidad. Sinergias educativas, v. 4, n. 2, p. 1-13, 2019.

RODRÍGUEZ, M. E. Visiones rizomáticas de la enseñanza de la matemática como decolonialidad.

IE: Revista de investigación educativa de la Rediech, v. 11, e836, p.1-17, 2020a. DOI: https://doi.org/10.33010/ie rie rediech.v11i0.836

RODRÍGUEZ, M. E. La educación matemática decolonial transcompleja como antropolítica. ESTUDIOS: Utopía y praxis latinoamericana, n. 4, p. 125-137, 2020 b.

RODRÍGUEZ, M. E. Religar ecosóficamente como urgencia transepistémica en la re-civilización de la humanidad. Revista Desenvolvimento Social, v. 26, n. 1, p. 169-188, enero/jun. 2020c. DOI: https://doi.org/10.46551/issn2179-6807v26n1p169-188

RODRÍGUEZ, M. E.; MOSQUEDA, K. Aportes de la pedagogía de Paulo Freire en la enseñanza de la matemática: hacia una pedagogía liberadora de la matemática. Revista Educación y Desarrollo Social, v. 9, n. 1, p. 82-95, enero/jun. 2015.

Práxis Educativa, Ponta Grossa, v. 16, e2117161, p. 1-15, 2021 Disponível em: <https://www.revistas2.uepg.br/index.php/praxiseducativa> 
SAID, E. Representaciones del intelectual. Buenos Aires: Paidós, 1996.

SKOVSMOSE, O. Investigación, práctica, incertidumbre y responsabilidad. En: VALERO, P.; SKOVSMOSE, O. (ed.). Educación matemática crítica: una visión sociopolítica del aprendizaje y la enseñanza de las matemáticas. Colombia: Universidad de los Andes, 2012. p. 261-370.

YEDAIDE, M. Fanon, Freire y las posibilidades concretas de una pedagogía descolonial: entrevista a Inés Fernández Mouján. Revista Entramados Educación y Sociedad, v. 3, n. 1, p. 33-41, 2014.

Recibido: 07/12/2020

Versión corregida recibida: 12/02/2021

Aceptado: 13/02/2021

Publicado online: $16 / 02 / 2021$ 